\title{
ASSESSMENT OF PHARYNGEAL AIRWAY IN UNILATERAL ADULT CLEFT LIP AND PALATE PATIENTS USING THREE-DIMENSIONAL METHODS
}

\author{
Ayman R. Khalifa*, Adel Rashid ${ }^{* *}$, Maggie A.Khairy ${ }^{* * *}$ and Essam M. Ashour ${ }^{* * *}$
}

\begin{abstract}
Aim: The objective of this study was to establish the characteristics of the nasopharyngeal airway in adult cleft lip/palate subjects (CLP), and to compare them with normal adult subjects using three-dimensionally cone beam computed tomography images (3D CBCT).

Subjects and Methods : The sample comprised control subjects $(n=15)$ and adult unilateral cleft lip/palate subjects $(n=15)$. Eighty-seven scans derived from 3D CBCT of the two groups were analyzed. A set of airway, and group of volumetric parameters were measured. CBCT scans were coded and measurements Landmarks were identified and measured using Dolphin 3D Imaging software server (version 11.7; Patterson Dental Supply, Chatsworth,Calf.).
\end{abstract}

Results: All the volumetric measurements of the cleft group showed significant lower total volume for Nasal Cavity, Nasopharynx ,Oropharynx ,Hypopharynx and total airway volume than the control group.

Conclusion: Adult unilateral CLP subjects had smaller nasopharyngeal parameters relative to normal adult subjects.

\section{INTRODUCTION}

Clefts of the lip and/or palate (CLP) is the most common craniofacial birth defect, occurring with a worldwide incidence of $\sim 1$ in 700 live births ${ }^{(1)}$. Orofacial clefts represents a complex interplay between genetic predisposition and environmental risk factors ${ }^{(2)}$.
Pharyngeal size plays an important role in speech and respiratory function. Previous studies have demonstrated significant differences in craniofacial structures in CLP patients compared with those in normal subjects ${ }^{(3)}$. CLP patients have a diminished upper airway volume compared with normal controls (Dixon et al, 2011). Many of CLP patients retain speech problems after the surgical

\footnotetext{
* Lecturer of Orthodontics, 6 October University, Faculty of Dentistry, Giza, Egypt.

** Lecturer of Orthodontics, Faculty of Dentistry, Fayoum University, Egypt.

*** Associated Professor of Maxillofacial Surgery, Faculty of Dentistry, Giza, Egypt.
} 
correction of cleft defects (e.g. palatoplasty) ${ }^{(4)}$. Therefore, a percentage of children with CLP are at high risk for sleep-disorders ${ }^{(5)}$. Sleep-disordered breathing is a spectrum of conditions that frequently impact the person ability to get enough quality of sleep. In children, CLP increases the risk for the sleep-disordered breathing due to the dysfunction of muscles controlling the soft palate in conjunction with structural abnormalities of the maxilla and the mandible ${ }^{(6)}$. Furthermore, CLP patients are at increased risk for hypertension, cardiovascular and cerebrovascular diseases, and excessive daytime sleepiness (7). In CLP patients, the associated craniofacial features include midface deficiency, retrognathic mandible resulting in the reduction of the pharyngeal airway volume ${ }^{(6)}$. All previously mentioned research indicates that The condition of the upper airway is an important field for orthodontists. Therefore, morphometric evaluation of the pharyngeal airway in patients with CLP is important $^{(8)}$.

Two-dimensional (2D) cephalometrics are the most commonly used by orthodontists to measure size and relative proportions of pharyngeal airway, but 2D measurements are inaccurate and prone to errors especially in the 2D interpretation of 3-dimensional (3D) structures ${ }^{(9)}$.

Technological advances in imaging have led to accurate three-dimensional (3D), high resolution digital records of hard and soft tissues. Several imaging technologies, such as spiral or helical computed tomography (CT) and dental cone-beam computed tomography (CBCT), are widely acting as diagnostic and research instruments in orthodontics and craniofacial surgeries ${ }^{(10,11)}$. There is an increasing agreement on the reliability of CBCT $3 \mathrm{D}$ assessment of the pharyngeal airway volume $(12,13,14,15)$. Using CBCT technologies, investigators studying airway patency, function and disorders; provided promising preliminary data including dimensions of airway anatomy in normal adults ${ }^{(10)}$.
Three-dimensional CBCT images offer an accurate representation of the airway.

Using CBCT, several studies demonstrated the differences in the nasopharyngeal airway volume with CLP growing subjects compared to normal subjects $^{(16,17,18,19,20)}$.

Therefore, the main purpose of this study was to establish the characteristics of the pharyngeal airway in adult CLP subjects, and to compare them with well matching control groups of normal adult subjects using $\mathrm{CBCT}$, in addition to investigating the gender differences between groups.

\section{MATERIAL AND METHODS}

This retrospective study was developed on subjects recruited from the department of maxillofacial and plastic surgery, School of Dentistry, 6 October University, Giza, Egypt. All patients and patients caregivers had signed an informed consent for allowing the use of their data for scientific purposes. We obtained the ethical committee approval was obtained to use deidentified CBCT scans from patients with/without CLP who had undergone preoperative CBCT imaging at the department of oral radiology.

The exclusion criteria were: history of orthognathic surgical repair, history of airway abnormalities or pathosis. A further exclusion criterion for the control group included any type of syndrome or craniofacial anomalies. All individuals with CLP had no pre-operative orthodontic intervention.

\section{The sample of the study included 30 subjects and were classified into :}

\section{1- Unilateral cleft adult (UCLP) with cleft in the left side :}

15 subjects patients ( 8 males - 7 females) were included. The age range for adult cleft subjects was between 18-27 years, 


\section{2- The normal Non CLP sample included:}

Non -Growing : 15 subjects ( 8 males -7 females) with (age range between 18-27 years).

The CBCT images were obtained using ILUMA Ultra Cone Beam CT Scanner system, KODAK 9000 3D System, IMTEC Imaging Corporation, Ardmore, Oklahoma). Each scan took 40 seconds and had Grayscale 16 bit (31744-45811 shades of gray). It gives 1:1 scale images, and CT slices thickness $0.28 \mathrm{~mm}$.

The CBCT images were uploaded into Dolphin 3D imaging software server (version 11.7; Patterson Dental Supply, Chatsworth, Calif) then measured and viewed on the same computer and monitor. Table (I) and Figure (1). All CBCT images were coded, and information on age and sex was recorded.

The prevertebral soft-tissue thickness was measured as the distance parallel to the Frankfort horizontal plane from 3 points on the CV 2, CV 4 to the posterior wall of the airway. Bony structure and soft tissue transposed on each other in midsagittal plane with the 3D Dolphin imaging system.

\section{Statistical Analysis:}

Kolmogorov-Smirnov test showed a nonparametric data distribution for tested parameters. Kruskal Wallis test used to compare between tested groups followed by Mann-Whitney U test for pairwise comparison. Mann-Whitney test was used to compare between Male and female groups. $(\alpha=0.05)$.

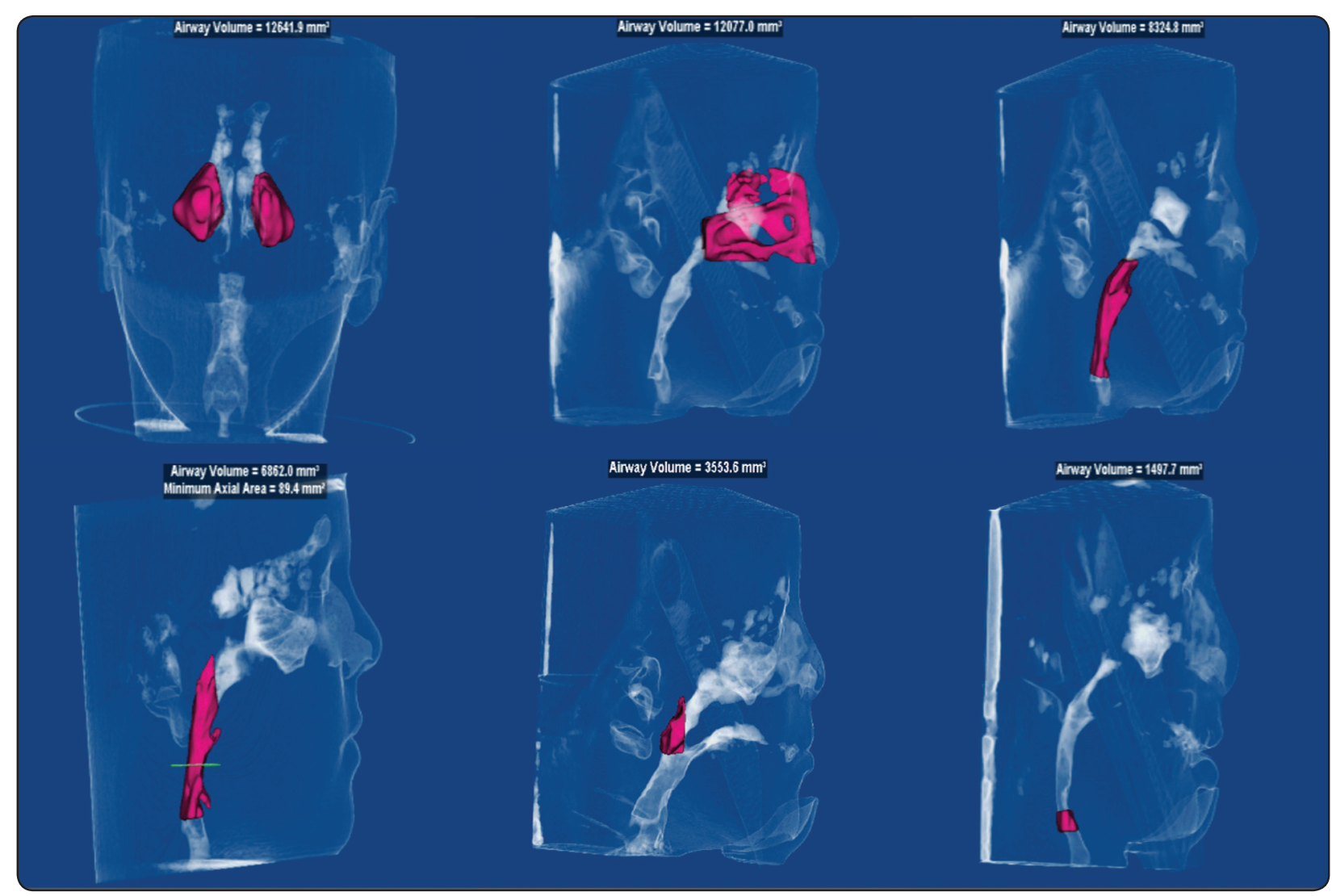

Fig. (1) Airway segmentation and volume and minimal area measurements. Screenshots from Dolphin software, show the segmentation and volume measurement of the airway space as shown in table (1). From top left to right, nasal cavity, nasopharynx, and oropharynx are segmented and measured. 
TABLE (1) : Definitions of volumetric parameters of the airway and the maxillary sinuses

\begin{tabular}{|c|c|c|c|c|}
\hline & Anterior boundary & Posterior boundary & Superior boundary & Inferior boundary \\
\hline Nasal cavity & $\begin{array}{l}\text { Line connecting the } \\
\text { anterior nasal spine } \\
\text { (ANS) to the tip of the } \\
\text { nasal bone to nasion }(\mathrm{N})\end{array}$ & $\begin{array}{l}\text { Line extending from } \\
\text { sella }(\mathrm{S}) \text { to the posterior } \\
\text { nasal spine (PNS) }\end{array}$ & $\begin{array}{c}\text { Line connecting } \mathrm{N} \\
\text { to } \mathrm{S}\end{array}$ & $\begin{array}{c}\text { from the ANS to the } \\
\text { PNS }\end{array}$ \\
\hline Nasopharynx & $\begin{array}{l}\text { Line extending from } \\
\text { sella }(\mathrm{S}) \text { to the posterior } \\
\text { nasal spine (PNS) }\end{array}$ & $\begin{array}{c}\text { Line extending from } S \\
\text { to the tip of the odontoid } \\
\text { process (Odp) }\end{array}$ & & $\begin{array}{l}\text { Line extending from } \\
\text { the PNS to tip of the } \\
\text { odontoid process (Odp) }\end{array}$ \\
\hline Oropharynx & $\begin{array}{l}\text { Line extending from the } \\
\text { posterior nasal spine } \\
\text { (PNS) to the body of } \\
\text { hyoid bone } \\
\text { (H) }\end{array}$ & $\begin{array}{l}\text { Line extending from } \\
\text { the tip of the odontoid } \\
\text { process (Odp) to the } \\
(\mathrm{C} 4 \mathrm{sp}) \text { posterior- } \\
\text { superior border of } \mathrm{CV} 4\end{array}$ & $\begin{array}{l}\text { Line extending from } \\
\text { the PNS to the tip of } \\
\text { the odontoid process }\end{array}$ & $\begin{array}{l}\text { Line extending from } \\
\text { the body of hyoid bone } \\
\text { to }(\mathrm{C} 4 \mathrm{sp}) \text { the posterior- } \\
\text { superior border of } \mathrm{CV} 4\end{array}$ \\
\hline Hypopharynx & $\begin{array}{l}\text { Line extending from the } \\
\text { body of hyoid bone }(\mathrm{H}) \\
\text { to the inferior border of } \\
\text { the symphysis }\end{array}$ & $\begin{array}{l}\text { Line extending from } \\
(\mathrm{C} 4 \mathrm{sp}) \text { the posterior- } \\
\text { superior corner of } \mathrm{CV} 4 \\
\text { to }(\mathrm{C} 4 \mathrm{ip}) \text { the posterior- } \\
\text { inferior corner of } \mathrm{CV} 4\end{array}$ & $\begin{array}{l}\text { Line extending from } \\
\text { the body of hyoid } \\
\text { bone to }(\mathrm{C} 4 \mathrm{sp}) \text { the } \\
\text { posterior-superior } \\
\text { corner of } \mathrm{CV} 4\end{array}$ & $\begin{array}{l}\text { Line extending from } \\
\text { (C4ip) the posterior- } \\
\text { inferior corner of } \mathrm{CV} 4 \\
\text { to the inferior border of } \\
\text { the symphysis }\end{array}$ \\
\hline \multicolumn{3}{|c|}{ Maxillary sinus } & $\begin{array}{l}\text { spects of he maxillar } \\
\text { tion }\end{array}$ & inus as seen on a section \\
\hline
\end{tabular}

\section{RESULTS}

\section{1- Pharyngeal airway difference between cleft and control subjects :}

For Nasopharynx and Oropharynx all volumetric measurements showed that cleft subject had nonsignificant lower total volume than normal ones . Tables II,III .For hypopharynx , male cleft subject had significant higher volume than normal male subjects . Table IV

\section{2- Gender difference :}

For Nasopharynx, Female subjects showed nonsignificant higher values compared to Males in cleft subjects. Table II

For Oropharynx and Hypopharynx, Male subjects showed non significant higher values compared to Female ones in the two groups cleft and control. Tables III and IV.

TABLE (II) : Nasopharynx volume difference between the two groups :

\begin{tabular}{|c|c|c|c|c|c|c|c|c|c|c|}
\hline & \multicolumn{8}{|c|}{ Gender } & \multirow{3}{*}{ p-value } \\
\hline & & \multicolumn{4}{|c|}{ Male } & \multicolumn{4}{|c|}{ Female } & \\
\hline & & Mean & SD & Min. & Max. & Mean & SD & Min. & Max. & \\
\hline \multirow{2}{*}{ 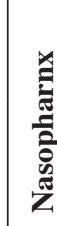 } & $\begin{array}{c}\text { Adult } \\
\text { Unilateral }\end{array}$ & 2058.14 & 1055.59 & 575.80 & 3474.40 & 3134.98 & 2384.96 & 449.70 & 7142.70 & $0.363 \mathrm{NS}$ \\
\hline & $\begin{array}{l}\text { Control } \\
\text { Adult }\end{array}$ & 5849.87 & 3097.96 & 3164.00 & 11736.60 & 3397.46 & 2297.35 & 316.20 & 8641.60 & $0.101 \mathrm{NS}$ \\
\hline
\end{tabular}


TABLE (III) : Oropharynx volume difference between the two groups :

\begin{tabular}{|c|c|c|c|c|c|c|c|c|c|c|}
\hline & \multicolumn{8}{|c|}{ Gender } & \multirow{3}{*}{ p-valuc } \\
\hline & & \multicolumn{4}{|c|}{ Male } & \multicolumn{4}{|c|}{ Female } & \\
\hline & & Mean & SD & Min. & Max. & Mean & SD & Min. & Max. & \\
\hline \multirow{2}{*}{ } & $\begin{array}{c}\text { Adult } \\
\text { Unilateral }\end{array}$ & 21476.35 & 12407.66 & 6563.90 & 36633.20 & 14546.00 & 5882.56 & 8379.10 & 26881.70 & $\begin{array}{c}0.187 \\
\mathrm{NS}\end{array}$ \\
\hline & $\begin{array}{l}\text { Control } \\
\text { Adult }\end{array}$ & 25725.30 & 12451.45 & 15510.40 & 48961.20 & 16156.99 & 4610.64 & 8680.90 & 24904.70 & $\begin{array}{c}0.053 \\
\mathrm{NS}\end{array}$ \\
\hline
\end{tabular}

TABLE (IV) : Hypopharynx volume difference between the two groups :

\begin{tabular}{|c|c|c|c|c|c|c|c|c|c|c|}
\hline & \multicolumn{8}{|c|}{ Gender } & \multirow{3}{*}{ p-valuc } \\
\hline & & \multicolumn{4}{|c|}{ Male } & \multicolumn{4}{|c|}{ Female } & \\
\hline & & Mean & SD & Min. & Max. & Mean & SD & Min. & Max. & \\
\hline \multirow{2}{*}{ 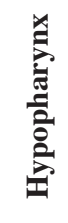 } & $\begin{array}{c}\text { Adult } \\
\text { Unilateral }\end{array}$ & 9876.93 & 12780.53 & 1383.00 & 24575.30 & 2645.34 & 1151.85 & 831.10 & 3804.90 & $\begin{array}{c}0.231 \\
\text { NS }\end{array}$ \\
\hline & $\begin{array}{l}\text { Control } \\
\text { Adult }\end{array}$ & 3216.60 & 851.94 & 2070.20 & 4581.70 & 2870.36 & 1040.59 & 1287.40 & 4177.50 & $\begin{array}{c}0.511 \\
\mathrm{NS}\end{array}$ \\
\hline
\end{tabular}

\section{DISCUSSION}

The aim of the study was to compare the pharyngeal airway dimensions using 3D CBCT images in adult subjects with CLP and compare the findings to a non-CLP control group, matched for age and sex, using CBCT.

Few studies evaluated pharyngeal airway volumes in patients with CLP considering age and gender. ${ }^{(1,6,7)}$ Some of these studies had limitations like, the usage of post-orthodontic CBCT images, ${ }^{(7)}$ small sample size, ${ }^{(1,6,7)}$ the combination of UCLP and BCLP patients affected by both UCLP and BCLP. ${ }^{(6,7)}$ In this study, the drawbacks of previous studies have been eliminated. For ethical reasons, CBCT used data of adults without CLP who had no congenital anomalies but submitted for other non-syndromic abnormalities or lesions (impacted canines, periapical lesions).
Cone beam computed tomography can threedimensionally assess the morphology of the airway space than conventional 2D radiography. CBCT, providing 3D images for the evaluation of pharyngeal airways, was found to be more accurate and reproducible than cephalometric techniques $^{(1)}$ On the other hand, similar quality images by CBCT technology can be offered by much lower doses of radiation, ${ }^{(5)}$ and thus the use of CBCT for airway evaluation has been suggested by many authors ${ }^{-(1,6,7,8)}$

In present study, findings showed that the lower airway width, upper adenoid width, nasal fossa length, McNamara lower pharynx and total pharyngeal area were smaller in CLP subjects without significant difference. However, upper aerial width tended to increase in CLP subjects. Furthermore, there was sexual dimorphism in both groups. 
In the present study, there was no significant differences in the airway volume between CLP and non-CLP patients. These volumetric findings contradict prior work published by Karia, Shrivastav and Karia ${ }^{(21)}$, who compared the anteroposterior dimensions of the oropharyngeal airway, the height of the oropharyngeal column, and the volume of the oropharyngeal airway in subjects with and without CLP. The authors found that oropharyngeal airway volume was lower in CLP patients than in non-CLP patients. ${ }^{(21)}$

In the present study,comparisons of the total oropharyngeal volume showed that it seemed to increase from the prepubertal to the postpubertal stages in both unilateral and bilateral CLP groups. Furthermore, it was found that men tended toward having bigger airways than women. Ronen et al reported a differential growth in airway between boys and girls during puberty, resulting in significantly longer airways in boys ${ }^{(20)}$.

\section{CONCLUSION :}

1. Volumetric measurements showed that CLP subjects had non-significant smaller Nasopharyngeal, Oropharyngeal and female Hypopharyngeal parameters relative to nonCLP subjects in the adult groups.

2. Hypopharyngeal volume was non significantly larger in CLP males compared to control group.

\section{REFERENCES}

1. Dixon MJ, Marazita ML, Beaty TH, Murray JC. Cleft lip and palate: understanding genetic and environmental influences. Nat Rev Genet. 2011;12:167-178.

2. Ahluwalia M, Brailsfor SR, Tarelli E, Gilbert SC, Clark DT, Barnard K, Beighton D. Dental caries, oral hygiene, and oral clearance in children with craniofacial disorders. J Dent Res.2004;83:175-179.

3. Shkoukani MA, Chen M, Vong A. Cleft Lip - A Comprehensive Review. Front Pediatr. 2013;1:53.
4. Fu Z, Lin Y, Ma L, Li W. Effects of maxillary protraction therapy on the pharyngeal airway in patients with repaired unilateral cleft lip and palate: A 3-dimensional computed tomographic study. Am J Orthod Dentofacial Orthop. 2016;149:673-82.

5. MacLean J E, Hayward P, Fitzgerald D A, Waters K. Cleft lip and/or palate and breathing during sleep. Sleep Med Rev. 2009;13:345-54.

6. Oosterkamp BCM, Remmelink HJ, Pruim GJ, Hoekema A, Dijkstra PU. Craniofacial, craniocervical, and pharyngeal morphology in bilateral cleft lip and palate and obstructive sleep apnea patients. Cleft Palate Craniofac J. 2007;44:1-7

7. Marcus C L. Clinical and pathophysiological aspects of obstructive sleep apnea in children. Pediatr Pulmonol Suppl.1997;16:123-24.

8. Aboudara C, Nielsen I, Huang JC, Maki K, Miller AJ, Hatcher D. Comparison of airway space with conventional lateral head films and 3-dimensional reconstruction from cone beam computed tomography. Am J Orthod Dentofacial Orthop. 2009;135:468-79.

9. Baumrind S, Frantz RC. The reliability of head film measurements. 2. Conventional angular and linear measures. Am J Orthod Dentofacial Orthop. 1971;60: 505-17.

10. Ghoneima A, Kula K. Accuracy and reliability of conebeam computed tomography for airway volume analysis. The European Journal of Orthodontics. 2011 Aug 10;35(2):256-61.

11. Shaheen E, Shujaat S, Saeed T, Jacobs R, Politis C. Threedimensional planning accuracy and follow-up protocol in orthognathic surgery: a validation study. International journal of oral and maxillofacial surgery. 2018 Aug 3.

12. Grauer, D., Cevidanes, L.S.H., \& Proffit, W.R. (2009). Working with DICOM craniofacial images. Am J Orthod Dentofacial Orthop 136, 460-470 .

13. El H, Palomo JM. Airway volume for different dentofacial skeletal patterns. Am J Orthod Dentofacial Orthop. 2011;139:511-21.

14. Nur M, Kayipmaz S, Bayram M, Celikoglu M, Kilkis D, Sezgin OS. Conventional frontal radiographs compared with frontal radiographs obtained from cone beam computed tomography. Angle Orthod. 2012;82:579-584.

15. Xu Y, Zhao SF and Shi JY. 3-dimensional computed tomographic analysis of the pharynx in adult patients with unrepaired isolated cleft palate. J Oral and Maxillofac Surg. 2013;71:1424-34. 
16. Patcas R, Müller L, Ullrich O, Peltomäki T. Accuracy of cone-beam computed tomography at different resolutions assessed on the bony covering of the mandibular anterior teeth. Am J Orthod Dentofacial Orthop 2012 Jan 1;141(1):41-50.

17. Smith T, Ghoneima A, Stewart K, Liu S, Halum S, Eckert G, Kula K. Three dimensional computed tomography analysis of airway volume changes following rapid maxillary expansion. Am J Orthod Dentofacial Orthop 2012;141:618-26

18. Al-Fahdawi, M.A., El-Kassaby, M. A., Farid, M.M and ElFotouh, M. A. (2016). Cone Beam Computed Tomography Analysis of Oropharyngeal Airway in Preadolescent
Nonsyndromic Bilateral and Unilateral Cleft Lip and Palate Patients. The Cleft Palate-Craniofacial Journal.

19. Abramson Z1, Susarla S, Troulis M, Kaban L. Age-related changes of the upper airway assessed by 3-dimensional computed tomography.J Craniofac Surg. 2009 Mar; 20 Suppl 1: 657-63.

20. Ronen O, Malhotra A, Pillar G. Influence of gender and age on upper airway length during development. Pediatrics 2007;120:1028-1034.

21. Karia H , Shrivastav S and Karia AK. Three-dimensional evaluation of the airway spaces in patients with and without cleft lip and palate: A digital volume tomographic study. Am J Orthod Dentofacial Orthop 2017;152:371-381 